\title{
Pathogenicity Determinants in the Complex Virus Population of a Plum pox virus Isolate
}

\author{
Pilar Sáenz, ${ }^{1}$ Laurence Quiot, ${ }^{2}$ Jean-Bernard Quiot, ${ }^{2}$ Thierry Candresse, ${ }^{3}$ and Juan Antonio García ${ }^{1}$ \\ ${ }^{1}$ Centro Nacional de Biotecnología (C.S.I.C.), Campus de la Universidad Autónoma de Madrid, 28049 \\ Madrid, Spain, ${ }^{2}$ Ecole Nationale Superieure Agronomique de Montpellier (ENSAM-INRA), 2 Place Viala, \\ 34060 Montpellier Cedex 1, France; 'UMR GD2P, IBVM, INRA, BP81, 33883 Villenave d'Ornon Cedex, \\ France \\ Accepted 22 November 2000.
}

\begin{abstract}
Several subisolates were separated from a single Plum pox virus (PPV) isolate, PPV-PS. In spite of an extremely high sequence conservation (more than $99.9 \%$ similarity), different subisolates differed largely in pathogenicity in herbaceous hosts and infectivity in woody plants. The severity of symptomatology did not seem to correlate with virus accumulation. Sequence analysis and site-directed mutagenesis demonstrated that single amino acid changes in the helper component (HC) protein caused a drastic effect on virus symptoms in herbaceous hosts and notably modified virus infectivity in peach seedlings. These results indicate that $\mathrm{HC}$ variation might play an important role in virulence evolution of natural plant virus infections. Moreover, the analysis of Potato virus $X$ (PVX)-HC chimeras showed that the identified $\mathrm{HC}$ amino acid changes had parallel effects on the severity of symptoms caused by PPV and on $\mathrm{HC}$-induced enhancement of PVX pathogenicity, indicating that $\mathrm{HC}$ functions in potyvirus symptomatology and in synergism with other viruses have overlapping determinants.
\end{abstract}

Plum pox virus (PPV) is a potyvirus causing the Sharka disease in Prunus trees, which results in important economic losses (López-Moya et al. 2000). Numerous PPV isolates have been described, and most of them can be classified into two major groups, M and D (Bousalem et al. 1994; Candresse et al. 1998). The atypical El Amar isolate (Wetzel et al. 1991) and the recently described sweet-and-sour cherry isolates have been assigned to two additional minor groups (Crescenzi et al. 1997; Nemchinov et al. 1996).

PPV-PS is a M-type isolate (Cervera et al. 1993). In general, PPV isolates belonging to the $\mathrm{M}$ strain cause more severe disease outbreaks compared with D-type isolates as a result of a more efficient spread in peach orchards (Dallot et al. 1998). PPV-PS also infects several herbaceous hosts such as Nicotiana clevelandii, Nicotiana benthamiana, Nicotiana occidentalis, and Chenopodium foetidum. In N. clevelandii, this isolate produces severe symptoms characterized by the development of striking necrotic lesions in the inoculated leaves

Corresponding author: J. A. García; Fax: +34 91 5854506; E-mail: jagarcia@cnb.uam.es and intense systemic leaf curling and chlorotic mottling. Nevertheless, infectious RNA transcribed from a PPV-PS-derived full-length cDNA induced a symptomatology much milder than that described above (Sáenz et al. 2000), suggesting that virus variants with different virulence could coexist in the original PPV-PS isolate.

Potyviruses have a single-stranded RNA genome of approximately $10 \mathrm{~kb}$. The genomic RNA has a viral protein genome linked covalently to the $5^{\prime}$ end and is polyadenylated at the $3^{\prime}$ end. It encodes a single polyprotein that is proteolytically processed by self-encoded proteases into functional proteins (Revers et al. 1999; Riechmann et al. 1992). The replication of plus-stranded RNA genomes is carried out by RNA-dependent RNA polymerases. The lack of proofreading activity of these enzymes gives rise to high misincorporation frequencies (in the range of $10^{-4}$ to $10^{-5}$ substitutions per copied nucleotide) (Drake 1993; Mansky and Temin 1995). A consequence of this inherently high mutation rate is the generation of heterogeneous virus populations of closely related genomes, termed "quasispecies" (Eigen and Schuster 1979; Holland et al. 1992). In spite of this heterogeneity, viral genomes of a given isolate usually retain a unique consensus or master sequence, but which is able to evolve rapidly depending on the environmental conditions. The modification of the consensus sequence of a quasispecies can cause changes in the pathogenicity of the viral population. Moreover, it is not unusual that more than one viral population (fluctuating around each respective master sequence) may coexist in a single host, and disease symptoms may vary depending on the population that predominates at a given time (Domingo and Holland 1997; Domingo et al. 1996).

In this work, we segregated several viral subpopulations from the single virus isolate PPV-PS. Some of these segregated virus variants caused symptomatologies similar to those of the original PPV-PS isolate, whereas the phenotype of others closely resembled that of the progeny of transcripts of the pGPPVPS full-length cDNA clone (Sáenz et al. 2000). Nucleotide sequence analysis revealed more than $99.9 \%$ similarity among the different segregants. We demonstrate that single amino acid changes in the helper component $(\mathrm{HC})$ protein of PPV condition the subisolates' infection in herbaceous and natural woody hosts. 


\section{RESULTS}

\section{Phenotypically different virus variants separated from the PPV-PS isolate.}

Six PPV-PS subisolates were obtained from the original PPV-PS isolate by serial passages through local lesions in $C$. foetidum. These PPV-PS subisolates caused different types of symptomatology in several herbaceous hosts (Fig. 1 and Table 1). Some of the subisolates caused symptoms as severe as (PS 4.1.4 and 5.1.3) or more severe than (PS $10_{2}$ and $10_{7}$ ) those produced by the original PS isolate. In contrast, other subisolates caused a very mild symptomatology, very similar to that of viral progeny of transcripts from the cDNA clone pGPPVPS (denoted PS MCl).

The phenotype stability of PPV-PS subisolates 4.1.4, 5.1.3, 1.3.1, and $\mathrm{MCl}$ was studied by additional local lesion passages in $C$. foetidum with the original PPV-PS isolate as a control. Extracts from ten independent lesions derived from each virus were used to inoculate $N$. clevelandii plants. The experiment corroborated the heterogeneity of the original PPV-PS: five out of ten local lesions derived from the original isolate produced severe symptoms in $N$. clevelandii, whereas the mild phenotype was observed in plants inoculated with three lesions (inoculation with local lesion extracts failed in two cases). In contrast, all molecularly cloned (PS MCl) or lesionderived (PS 4.1.4, 5.1.3, 1.3.1) subisolates showed a stable phenotype, the symptomatology of each local lesion subisolate being similar to that of its parent. The percentage of single local lesions able to initiate a systemic infection in $N$. clevelandii was similar in all the lesion-derived subisolates and in the original PS isolate (70 to $80 \%$ ) and somewhat lower in the molecularly cloned subisolate PS $\mathrm{MCl}(50 \%)$, suggesting that the infectivity of all subisolates was comparable. In order to assess the infectivity of the different PPV-PS subisolates in natural woody hosts, seedlings of the GF305 peach indicator were sap inoculated with extracts of infected $N$. benthamiana plants. Viral accumulation was determined in inoculated and upper noninoculated leaves by enzyme-linked immunosorbent assay (ELISA) tests (Table 2). Subisolates PS 4.1.4 and 5.1.3 showed a high infectivity in GF305 peach. Efficient systemic spread was observed in almost all seedlings inoculated with these subisolates, and development of visible symptoms could

Table 1. Symptoms caused by different Plum pox virus (PPV) PS subisolates in several herbaceous hosts

\begin{tabular}{llll}
\hline Virus & \multicolumn{1}{c}{$\begin{array}{c}\text { Nicotiana } \\
\text { clevelandii }^{\text {a, }} \text { }\end{array}$} & $\begin{array}{c}\text { Nicotiana } \\
\text { benthamiana }^{\text {a,b }}\end{array}$ & $\begin{array}{c}\text { Nicotiana } \\
\text { occidentalis }^{\text {a,b }}\end{array}$ \\
\hline 4.14 & NL/SCM+LCu & $-/ M i M o$ & NL/MoCM+VN \\
5.1 .3 & NL/SCM+LCu & $-/ M i M o$ & NL/MoCM+VN \\
1.3 .1 & SbL/MiCM & $-/ M i M o$ & SbL/MoCM \\
2.1 .1 & SbL/MiCM & $-/ M i M o$ & SbL/MoCM \\
$10_{7}$ & NL/SCM+SNL+Lcu & Wilting & NL/MoCM+VN \\
$10_{2}$ & NL/SCM+SNL+Lcu & Wilting & NL/MoCM+VN \\
PS Ori $^{c}$ & NL/SCM+LCu & $-/ M i M o$ & NL/MoCM+VN \\
PS MCl $^{\text {d }}$ & SbL/MiCM & $-/ M i M o$ & CL/MoCM \\
\hline
\end{tabular}

${ }^{\text {a }}$ Local/systemic symptoms.

${ }^{\mathrm{b}} \mathrm{NL}$ : necrotic lesions; SbL: subliminal lesions; CL: chlorotic lesions; SCM: severe chlorotic mottling; MoCM: moderate chlorotic mottling; MiCM: mild chlorotic mottling; MiMo: mild mosaic; Lcu: leaf curling; VN: veinal necrosis; SNL: systemic necrotic lesions.

${ }^{c}$ Original PPV-PS isolate.

${ }^{\mathrm{d}}$ Progeny of transcripts from pGPPVPS clone. be detected in about half. In spite of the aggressiveness of the subisolates PS $10_{7}$ and $10_{2}$ in the herbaceous hosts, infectivity in peach seedlings was low (approximately 30\%) and no disease symptoms could be detected on infected plants (Table 2). Interestingly, mild subisolates PS 1.3.1 and 2.1.1 seemed unable to infect GF305 peach seedlings.

\section{Correlation between virus accumulation} and symptomatology among subisolates from PPV-PS.

Viral accumulation in $N$. clevelandii plants infected with different PPV-PS subisolates was determined by serological analysis (Western blot analysis, not shown, and doubleantibody sandwich indirect [DASI]-ELISA) (Fig. 2). A notable variability was observed among the different subisolates as well as among the plants infected with the same virus (revealed by very high standard deviations). No correlation could be detected between virus accumulation and symptom severity. Thus, in the experiment reported in Figure 2, maximal virus accumulation was observed in plants infected with two severe (PS 4.1.4 and 5.1.3) and one mild (PS 2.1.1) subisolate, whereas the lowest level of accumulation corresponded to the most severe subisolates, PS $10_{7}$ and $10_{2}$, and to the mild subisolate PS $\mathrm{MCl}$.

\section{Genomic sequence of subisolate PPV-PS 4.1.4 differs from pGPPVPS only by four nucleotides.}

The complete nucleotide sequence of the PPV cDNA cloned in pGPPVPS has been reported (Sáenz et al. 2000). Because viral progeny of pGPPVPS (PS $\mathrm{MCl}$ ) caused a mild symptomatology, we sequenced the genome of PPV-PS 4.1.4, a severe subisolate. Nucleotide sequencing of PPV-PS 4.1.4 was carried out on partial cDNA fragments amplified directly by immunocapture-polymerase chain reaction (IC-PCR) from infected tissue. Nucleotide changes found in the PS 4.1.4 genome (confirmed in a second IC-PCR-amplified fragment) also were contrasted with partial sequences of the rest of subisolates.

Only four changes were detected when the nucleotide sequences of pGPPVPS and PS 4.1.4 were compared (Table 3). The A7793C heterogeneity in the NIb coding region does not change the amino acid sequence of the polyprotein, thus it is not expected to be involved in symptom specification. The C8711A change leads to a Phe45Leu substitution in the capsid protein $(\mathrm{CP})$. Because a $\mathrm{C}$ residue is found at position 8,711 of the subisolates PS $10_{2}$ and $10_{7}$ (Table 3), an A residue at this position (Leu45 in CP) is not essential for a severe phenotype. This conclusion is supported by a previous report of a Leu45Pro heterogeneity in a D-strain PPV isolate, which af-

Table 2. Infection of peach GF305 seedlings with different Plum pox virus PS subisolates

\begin{tabular}{lccc}
\hline Subisolates & Inoculated leaves $^{\mathbf{a}}$ & Systemic leaves $^{\mathbf{a}}$ & Symptoms $^{\mathbf{b}}$ \\
\hline PS 1.3 .1 & $0 / 12$ & $0 / 12$ & $0 / 12$ \\
PS 2.1 .1 & $0 / 12$ & $0 / 12$ & $0 / 12$ \\
PS 4.1.4 & $11 / 12$ & $9 / 10$ & $5 / 10$ \\
PS 5.1.3 & $11 / 11$ & $10 / 10$ & $6 / 10$ \\
PS $10_{7}$ & $4 / 12$ & $3 / 10$ & $0 / 10$ \\
PS $10_{2}$ & $1 / 12$ & $3 / 11$ & $0 / 10$ \\
\hline
\end{tabular}

${ }^{a}$ Number of infected plants assessed by enzyme-linked immunosorbent assay/number of assayed plants.

${ }^{\mathrm{b}}$ Number of plants showing visible symptoms/number of assayed plants. 
fected CP reactivity against a monoclonal antibody but had no apparent effect on symptoms in herbaceous hosts (Asensio 1996). Two nucleotide heterogeneities were detected in the sequence coding for the HC protein. This potyviral protein is involved in systemic movement, enhancement of pathogenicity, and suppression of gene silencing, among other processes. A $G$ residue was present at position 1,764 (giving rise to Gly231 in HC) in the subisolates responsible for mild phenotypes (Table 3). Conversely, all severe subisolates presented an A residue at this position (HC Ser231) (Table 3). The second heterogeneity in the $\mathrm{HC}$ coding region affected nucleotide
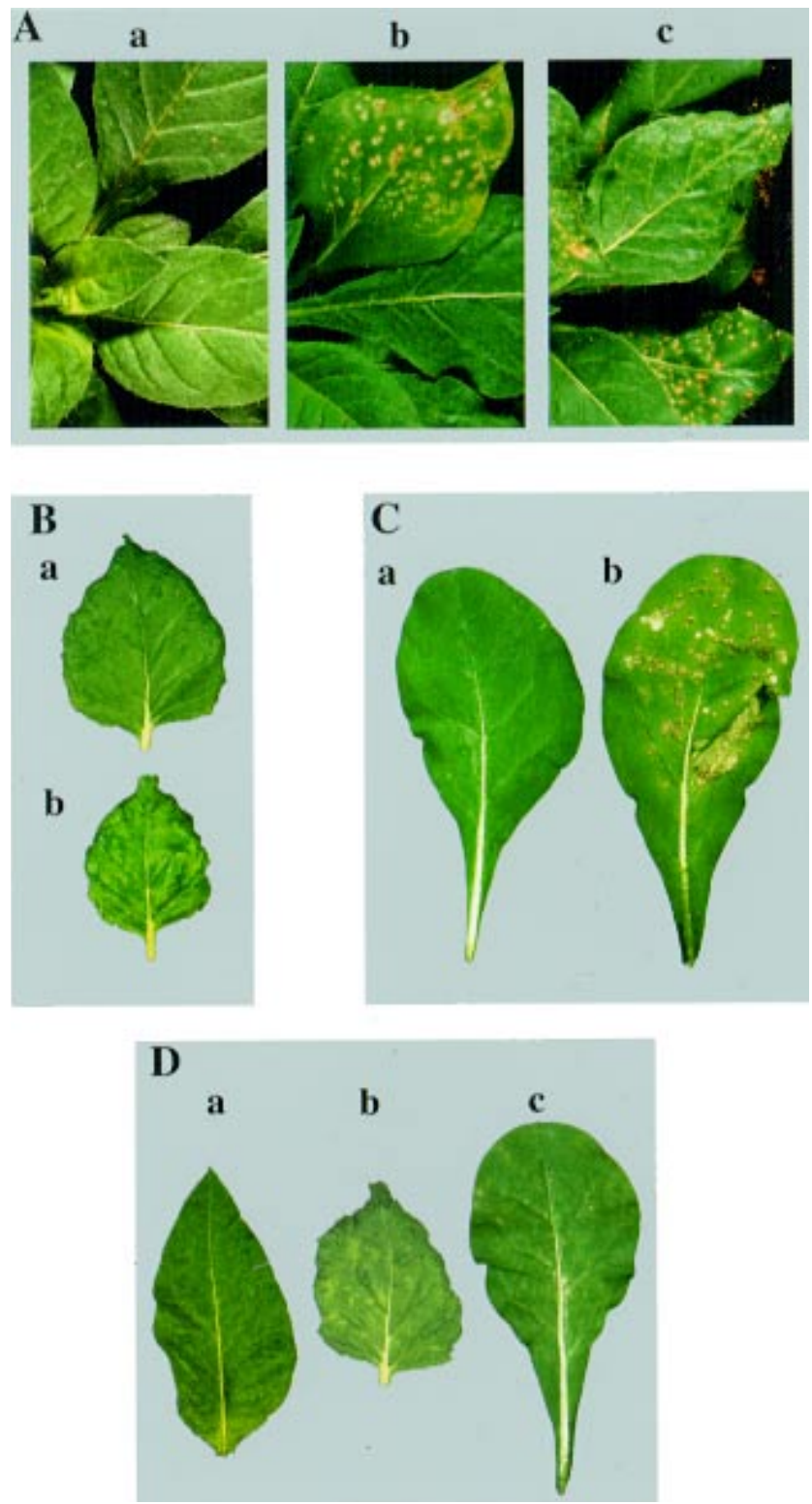

Fig. 1. Symptoms of Plum pox virus (PPV)-PS subisolates in different herbaceous plants. A, Nicotiana clevelandii plants infected with a) PPVPS 1.3.1, b) PPV-PS 4.1.4, and c) PPV-PS $10_{7}$. B, Detached systemically infected leaves of Nicotiana benthamiana plants inoculated with a) PPVPS 1.3.1 and b) PPV-PS 4.1.4. C, Detached inoculated leaves of Nicotiana occidentalis plants infected with a) PPV-PS 1.3.1 and b) PS 4.1.4. D, Detached systemically infected (a and b) or inoculated (c) leaves of three herbaceous hosts infected with the viral progeny of pGPPVPS. a) $N$. clevelandii, b) $N$. benthamiana, and c) $N$. occidentalis.
1,395. In this case, no apparent correlation with symptom phenotype was observed. There was an A residue at this position (Lys107 of HC protein) of pGPPVPS and a G residue (Glu107 of HC protein) in mild and severe subisolates derived by lesion passage from the original PPV-PS isolate (Table 3).

\section{Fragment of the $\mathrm{HC}$ coding sequence of PPV-PS 4.1.4 confers the severe phenotype.}

In order to assess the relevance of the nucleotide heterogeneities found in the PPV-PS HC coding region, a DNA fragment of pGPPVPS covering PPV sequence between nucleotides 1,334 and 2,312 was replaced by the corresponding fragment obtained by IC-PCR from PPV-PS 4.1.4-infected plants. The resulting plasmid, pGPPVPSE107S231, differed from $\mathrm{pGPPVPS}$ by the presence of $\mathrm{G}$ and A substituting for $\mathrm{A}$ and $\mathrm{G}$ at positions 1,395 and 1,764 , respectively. In vitro transcripts from pGPPVPSE107S231 reproduced the severe PS 4.1.4 phenotype in $N$. clevelandii and $N$. occidentalis plants (Fig. 3 and Table 4). The stability of these changes was verified by sequencing of the virus progeny.

The induction of severe symptoms by PPV-PS 4.1 .4 or PPV-PS E107S231 was temperature sensitive. Whereas $N$. clevelandii plants infected with these viruses at $24^{\circ}$ showed the typical severe symptoms mentioned above, infection at $30^{\circ}$ displayed an almost symptomless phenotype, although virus accumulation did not seem to be affected (data not shown). No genotype changes are apparent in virus progeny from plants infected at $30^{\circ}$ because the virus continued causing typical severe symptoms when back inoculated on plants at $24^{\circ}$ (not shown).

\section{Unique A1395G substitution in pGPPVPS confers a phenotype similar to that of PPV-PS 4.1.4.}

The severe PPV-PS E107S231 virus differs from PPV-PS $\mathrm{MCl}$ (mild) by two point mutations in the $\mathrm{HC}$ coding region, G1395A and A1764G. To determine the individual contribution of each change to the phenotype, two new cDNA clones were constructed. pGPPVPSE107G231 has G1395 and G1764

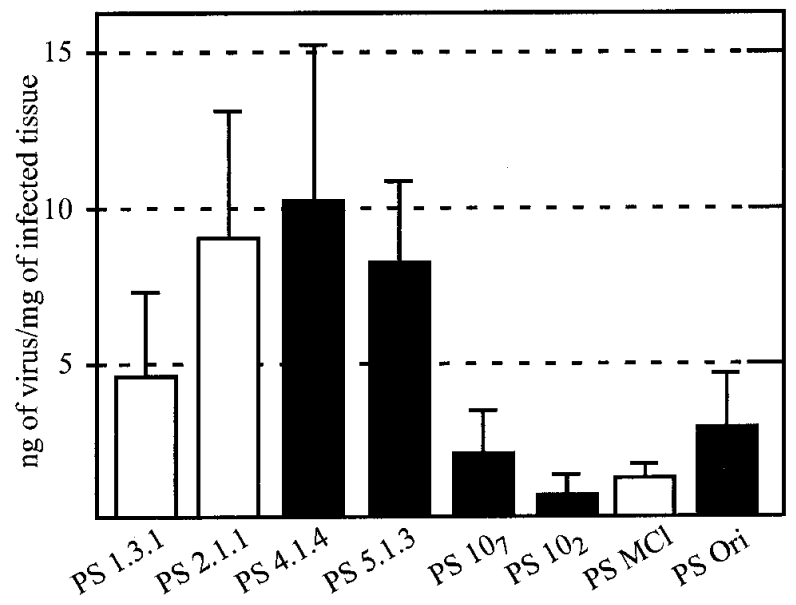

Fig. 2. Coat protein accumulation at 30 days postinoculation of different Plum pox virus-PS subisolates in extracts of infected Nicotiana clevelandii plants, estimated by double-antibody sandwich indirect enzymelinked immunosorbent assay. Bars represent average values of virus amounts of 16 independent samples for every subisolate. Black and white bars correspond to severe and mild subisolates, respectively. 
(Glu107 and Gly231 in HC protein) and pGPPVPSK107S231 has A1395 and A1764 (Lys107 and Ser231 in HC). Surprisingly, in spite of the strict correlation that we observed between $\mathrm{G}$ and $\mathrm{A}$ at position 1,764 and between mild to severe phenotypes, a single A for G substitution at position 1,764 had minor effects on symptomatology. Thus, virus progeny derived from pGPPVPSK107S231 transcripts produced a reduced number of necrotic lesions and a systemic chlorotic mottling in $N$. clevelandii that became slightly more marked than those caused by PPV-PS 1.3.1 or PS MCl (Fig. 3 and Table 4). In contrast, even though the severe subisolates PS 4.1.4 and 5.1.3 as well as the mild subisolates PS 1.3.1 and 2.1.1 have $\mathrm{G}$ at position 1,395. PPV-PS E107G231, which only differs from PPV-PS $\mathrm{MCl}$ in having a G1395 residue, caused necrotic lesions at the inoculated leaves and severe systemic symptoms that strongly resembled those caused by PPV-PS 4.1.4 (Fig. 3 and Table 4). This result demonstrates that an A residue at position 1,764 (Ser231 in HC protein) was not essential to the severe phenotype of PPV-PS 4.1.4. Similar results were obtained when $N$. occidentalis symptoms were analyzed. Lesions caused by PPV-PS E107G231 gave a rapid and intense necrotization similar to those caused by PPV-PS 4.1.4 and PS E107S231 (Fig. 3). In addition, necrosis of major veins in the upper leaves was observed in plants infected with these viruses (not shown). In contrast, only some of the lesions caused by PPV-PS K107S231 were necrotic, whereas the remainder were mostly chlorotic and resembled those caused by PPV-PS MCl (Fig. 3) with no veinal necrosis observed.
Point mutations in the HC coding region of PPV-PS affect virus infectivity in natural woody hosts.

Peach (GF305) seedlings were inoculated with PPV-PS $\mathrm{MCl}$, PS E107S231, PS E107G231, and PS K107S231 (Table $5)$. In contrast with the results in herbaceous plants, the most relevant position in Prunus spp. seems to be nucleotide 1,764 (HC amino acid 231) because PPV-PS K107S231 and PS E107S231 (A at position 1,764) showed efficiencies of infection higher than those of PPV-PS MCl and PS E107G231 (G at position 1,764). The higher percentage infectivity of PPVPS E107G231 ( $\mathrm{G}$ at position 1,395) compared with that of PPV-PS MCl (A at position 1,395), however, suggests that G1395 also may contribute to the infectivity of PPV-PS in peach.

\section{Glutamic acid residue at position 107 increases PPV HC protein capacity to enhance pathogenicity of Potato virus $X$.}

Previous studies have shown that the HC protein from several potyviruses is able to enhance the pathogenicity of other viruses such as Potato virus X (PVX) (Shi et al. 1997; Vance et al. 1995). In order to appraise whether the same genetic determinants are controlling symptom development in herbaceous hosts and enhancement of pathogenicity of another virus, sequences encoding PPV-PS HC (Lys107Gly231), HC (Glu107Ser231), HC (Lys107Ser231), and HC (Glu107Gly231) were inserted in the genome of PVX, making use of the pP2C2S cDNA clone (Chapman et al. 1992; Hammond and Kamo 1995). N. clevelandii and $N$. benthamiana plants

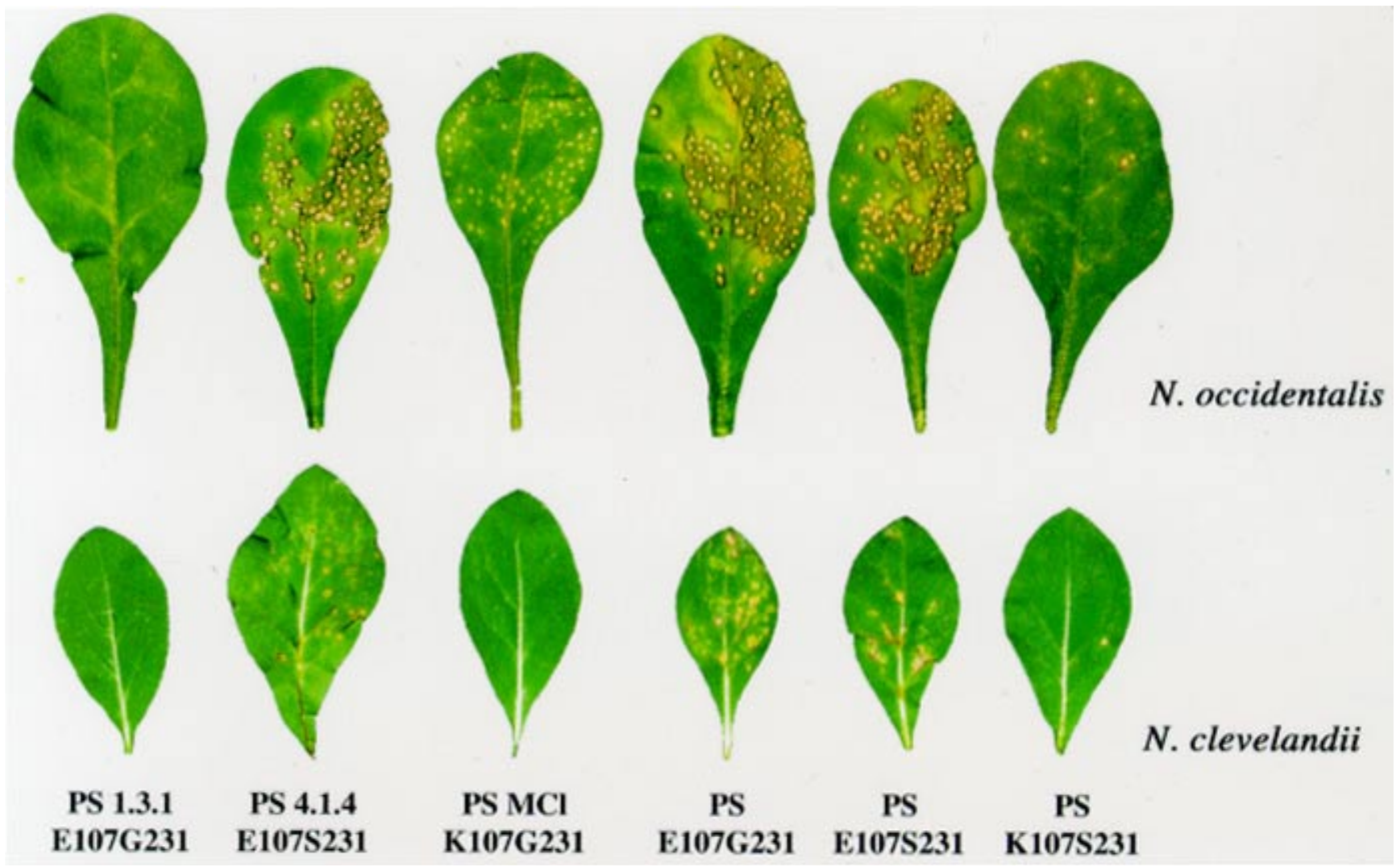

Fig. 3. Symptoms observed in inoculated leaves of Nicotiana occidentalis (upper part of figure) and Nicotiana clevelandii plants inoculated with virus progeny of different Plum pox virus (PPV)-PS cDNA clones (PS MCl and PS) and with the PPV-PS 4.1.4 and 1.3.1 subisolates. 
were inoculated with in vitro transcripts from the corresponding plasmids pPVX-HCK107G231, pPVX-HCE107S231, pPVX-HCK107S231, and pPVX-HCE107G231. None of the PVX-HC recombinant viruses caused lesions at the inoculated leaves similar to those caused by the severe PPV subisolates in $N$. clevelandii. All of them, however, exacerbated the mild symptomatology of wild-type PVX in $N$. clevelandii and $N$. benthamiana (Fig. 4). PVX causes mild chlorotic mottling and slight leaf curling in these hosts. These symptoms were significantly more intense in plants infected by PVXHCK107G231 and PVX-HCK107S231, which also showed systemic necrotic spots and severe stunting. Maximal enhancement of pathogenicity, however, was observed in plants infected with PVX recombinants carrying a PPV HC with Glu107, PVX-HCE107G231, and PVX-HCE107S231. These viruses caused symptoms so intense that plants suffered a generalized necrosis, wilted, and, in most cases, died.

\section{DISCUSSION}

The PPV-PS isolate was replicated in $N$. clevelandii as a complex virus population. Local lesion passages allowed us to separate several PPV-PS subisolates that displayed more than 99.9\% similarity, although differed remarkably in symptom severity in several herbaceous hosts. This result could be in agreement with a quasispecies distribution of PPV-PS (Domingo et al. 1996; Holland et al. 1992). Although the small number of subisolates we studied precludes a rigorous population genetics analysis, the amino acid changes observed do not seem to follow the expected distribution for random mutations introduced by the RNA replicase. $\mathrm{C}$ at position 7,793 and $\mathrm{A}$ at nucleotide 8,711 go together in PPV-PS 4.1.4 and PS 5.1.3, whereas $\mathrm{A}$ and $\mathrm{C}$ are at those positions in the remainder of the subisolates. Likewise, A at position 1,764 always is associated with $\mathrm{G}$ at position 1,395 (subisolates PS 4.1.4, 5.1.3, $10_{2}$, and $10_{7}$ ), but $\mathrm{G}$ at nucleotide 1,764 is accompanied by a $\mathrm{G}$ (subisolates PS 1.3 .1 and 2.1.1) or A (PS MCl) at position 1,395 (Table 3). These results suggest that several quasispecies, each one with a different master sequence, could coexist in the original PPV-PS population. This conclusion agrees with our observation that population complexity does not seem to be regained after further replication of the separated subisolates in $N$. clevelandii. The natural occurrence of hybrid viruses in PPV (Cervera et al. 1993) and other potyvirus (Revers et al. 1996) infections indicates that several viruses replicating in a more or less independent way in a single host plant may not be very unusual in potyviral infections. The PPV-PS isolate originated from a Yugoslavian-infected peach tree and belongs to the M strain. M-type isolates usu- ally are characterized by fast-spreading outbreaks in peach orchards. Unfortunately, plant material from the tree originally infected with PPV-PS no longer is available. Thus, we cannot determine whether the complex structure of the PPV-PS population already was present in the original infected tree or derived from its passage to a herbaceous host. The results indicate that divergence in pathological features of different subisolates was not restricted to herbaceous plants but also affected the natural woody hosts (Table 2). The fact that subisolates PPV-PS 1.3.1 and 2.1.1 were unable to infect GF305 peach seedlings suggests that they have been generated after transfer to the herbaceous host. However, we cannot discard the hypothesis that they could have been maintained in Prunus spp. through complementation by other members of the population.

There were striking pathogenicity differences in herbaceous hosts among the different PPV-PS subisolates. No correlation seems to exist, however, in $N$. clevelandii between symptom severity and accumulation of virus estimated by ELISA or by local lesion assay in C. foetidum (Fig. 2 and data not shown). Although these results suggest that enhancement of symptom severity is not the mere result of a more efficient virus replication, we cannot rule out that different progression rates of the subisolates in the first stages of infection could account for the differences in symptomatology. Further studies on the evolution of the noncloned PPV-PS population and of mixtures of different subisolates could help to establish relationships between symptom phenotype and viral fitness.

In order to identify the viral genetic elements that define the differences in pathogenicity between PPV-PS subisolates,

Table 4. Symptomatology caused by virus progeny of pGPPVPS mutants

\begin{tabular}{llll}
\hline Virus & \multicolumn{1}{c}{$\begin{array}{c}\text { Nicotiana } \\
\text { clevelandii }^{\text {a,b }}\end{array}$} & $\begin{array}{c}\text { Nicotiana } \\
\text { occidentalis }^{\text {a,b }}\end{array}$ & $\begin{array}{c}\text { Nucleotide } \\
\text { sequence }\end{array}$ \\
\hline $\begin{array}{c}\text { PS MCl } \\
\text { (K107G231) }\end{array}$ & SbL/MiCM & CL/MoCM & A1395G1764 \\
PS E107G231 & NL/SCM+LCu & NL/MoCM+VN & G1395G1764 \\
PS E107S231 & NL/SCM+LCu & NL/MoCM+VN & G1395A1764 \\
PS K107S231 & NL/MiCM & NL/MoCM & A1395A1764 \\
PS 4.1.4 & NL/SCM+LCu & NL/MoCM+VN & G1395A1764 \\
PS 1.3.1 & SbL/MiCM & SbL/MoCM & G1395G1764 \\
\hline
\end{tabular}

${ }^{\text {a }}$ Local/systemic symptoms.

b NL: necrotic lesions; SbL: subliminal lesions; CL: chlorotic lesions; SCM: severe chlorotic mottling; MoCM: moderate chlorotic mottling; MiCM: mild chlorotic mottling; LCu: leaf curling; VN: veinal necrosis.

c Slightly more marked systemic mottling.

d Small number of necrotic lesion lesions accompanied by non-necrotic lesions and a delayed chlorotic mottling.

Table 3. Genome and protein localization of sequence heterogeneities found in different Plum pox virus PS subisolates

\begin{tabular}{|c|c|c|c|c|c|c|c|c|}
\hline \multicolumn{4}{|c|}{ Gene-nucleotide position ${ }^{a}$} & \multirow[b]{2}{*}{ Subisolate $^{a}$} & \multicolumn{4}{|c|}{ Protein-amino acid position } \\
\hline HC $1,395^{b}$ & HC 1,764 & NIb 7,993 & CP 8,711 ${ }^{\mathrm{c}}$ & & HC 107 & HC 231 & NIb 257 & CP 45 \\
\hline$G$ & $A$ & $C$ & $A$ & PS 4.1.4, PS 5.1.3 & Glu & Ser & Ser & Leu \\
\hline $\mathrm{G}$ & $\mathrm{G}$ & A & $\mathrm{C}$ & PS 1.3 .1$, PS 2.1 .1 & Glu & Gly & Ser & Phe \\
\hline$G$ & $A$ & $C$ & $A$ & $P S 10_{7}, P S 10_{2}$ & Glu & Ser & Ser & $\mathrm{Leu}$ \\
\hline A & $\mathrm{G}$ & A & $\mathrm{C}$ & PS MCl & Lys & Gly & Ser & Phe \\
\hline
\end{tabular}

${ }^{\mathrm{a}}$ Italic and plain text indicates severe and mild isolates, respectively.

${ }^{\mathrm{b}} \mathrm{HC}=$ helper component $\mathrm{Nib}=$ nuclear inclusion $\mathrm{b}$ protein.

${ }^{\mathrm{c}} \mathrm{CP}=$ capsid protein. 
three experimental approaches were conducted: i) sequence analysis of cDNA fragments amplified by IC-PCR from extracts of infected plants, taking special care to discard PCR mistakes; ii) site-directed mutagenesis of pGPPVPS to assess the relevance of the sequence heterogeneities detected; and iii) further evaluation of sequence differences by heterologous expression of PPV proteins with a PVX-vector.

When the full-length sequence of the severe subisolate PPV-PS 4.1.4 was compared with the cDNA cloned in pGPPVPS, which confers a mild phenotype, only four nucleotide changes translated to three amino acid substitutions were found. Two amino acid substitutions were in the sequence coding for the multifunctional HC protein. Sequence analysis of other PPV-PS subisolates showed a precise correlation between severe symptomatology and $\mathrm{A}$ at position 1,764 of the genome (Ser231 of HC protein). When this mutation was introduced in pGPPVPS, however, symptoms caused by the resulting virus were slightly more pronounced than those of the pGPPVPS virus progeny. In contrast, an A to $\mathrm{G}$ substitution at position 1,395 (Lys107Glu in HC protein), alone (pGPPVPSE107G231) or in combination with the G1764A mutation (pGPPVPSE107S231), gave rise to a severe phenotype indistinguishable from those of subisolates 4.1.4 and 5.1.3. Therefore, a single nucleotide change in the HC coding region is sufficient to produce a dramatic change in symptoms without an apparent effect on virus accumulation. It is important to note that subisolates 1.3.1 and 2.1.1, despite having a $\mathrm{G}$ at position 1,395 (Glu107 of HC protein), produce very mild symptomatology. Because the HC sequences of PPV-PS 1.3.1 and 2.1.1 are identical to that of pGPPVPSE107G231 (responsible for a severe phenotype), undiscovered attenuating nucleotide change(s) should exist in the regions of PPV-PS 1.3.1 and 2.1.1 genomes that have not been sequenced.

Modulation of the symptomatology of its own virus and enhancement of PVX pathogenicity are two functions that have been attributed to the potyvirus HC protein. The fact that the effect of the Lys107Glu mutation is not specific for a PPV infection, but also affects the ability of PPV HC to enhance the pathogenicity of PVX (Fig. 4), provides additional support that these two HC functions should be closely linked.

The A7793C change does not modify the NIb protein sequence, and PPV subisolates with different residues at position 45 of the $\mathrm{CP}$ (affected by the C8711A substitution) have been described without apparent phenotypic changes in herbaceous hosts (Asensio 1996). Sequence analysis of the different PPV-PS subisolates, moreover, indicate that mild and severe phenotypes can be associated with C7793A8711 and A7793C8711 configurations (Table 3). These facts suggest that $\mathrm{A} 7793 \mathrm{C}$ and $\mathrm{C} 8711 \mathrm{~A}$ heterogeneities are not relevant for the phenotypic differences we are studying, although we cannot rule out the possibility that they may play a role in pathogenicity, especially in woody hosts.

It is important to recognize that point substitutions in the $\mathrm{HC}$ protein alter PPV infectivity in $P$. persicae, although their relative relevance is different in woody and herbaceous hosts (Table 5). These data highlight the relevance of HC protein in natural infections and provide further evidence on the host specificity of pathogenicity determinants. In addition, PPV-PS 1.3.1 and 2.1.1 (HC E107G231) were unable to infect GF305 peach in inoculated or in upper noninoculated leaves (Table 2 ), indicating that a genetic element required for replication or movement in some woody hosts (but not in herbaceous plants) and that is present in the genome of PPV $\mathrm{MCl}$ but outside the HC coding region was not functional in PPV-PS 1.3.1 and 2.1.1. We do not yet know whether this putative genetic element is the same that confers a mild phenotype to these two subisolates in herbaceous hosts. Moreover, PPV-PS $10_{2}$ and $10_{7}$, which cause the most severe phenotype in herbaceous hosts (Fig. 1 and Table 1), infect GF305 peach trees less efficiently than PPV-PS 4.1.4 and 5.1.3 (Table 2), although their HC sequences are identical. Thus, PPV-PS $10_{2}$ and $10_{7}$ probably still have unidentified genetic determinants outside the HC coding region that enhance pathogenicity in herbaceous plants and attenuate infectivity in woody hosts.

The potyvirus $\mathrm{HC}$ protein is a multifunctional molecule that seems to play a role in different steps of the viral infection cycle. In addition to its function in aphid transmission from which its name (helper component) is derived (Atreya et al. 1992; Thornbury et al. 1985), the HC protein, which is able to bind in vitro to RNA (Maia and Bernardi 1996; UrcuquiInchima et al. 2000) and has proteolytic activity (Carrington et al. 1989) is required for viral genome amplification (Klein et al. 1994), cell-to-cell and long-distance movement (Cronin et al. 1995; Rojas et al. 1997), affects symptom expression of its own virus (Atreya et al. 1992; Gal-On and Raccah 1999), and enhances the pathogenicity of other viruses in mixed infections (Vance et al. 1995). Moreover, recent results have demonstrated that $\mathrm{HC}$ has a role as a suppressor of posttranscriptional gene silencing (PTGS) (Anandalakshmi et al. 1998; Brigneti et al. 1998; Kasschau and Carrington, 1998), an important mechanism for plant defense against viruses. Extensive mutagenesis analysis has allowed for the identification of amino acid residues relevant for the different activities of the protein, although a modular structure with specific domains involved in each protein function cannot be envisaged (Fig. 5). In general, mutations in the central region of $\mathrm{HC}$ give rise to low levels of virus amplification in protoplasts as the result of early suppression of virus replication, and blocking of systemic movement (Kasschau et al. 1997; Klein et al. 1994), which seems to be linked to loss of its ability to enhance pathogenicity of other viruses (Shi et al. 1997). All these effects might be associated with defects in the suppressor of PTGS activity of the HC protein. However, the effects of HC mutations in virus amplification and systemic movement do not always correlate. Thus, some mutants that replicate very poorly in protoplasts are able to move efficiently throughout the plant (Cronin et al. 1995) and vice versa (Klein et al. 1994). Most of these findings have been obtained with potyvirus HC proteins modified by site-directed mutagenesis,

Table 5. Infectivity of virus progeny of pGPPVPS mutants in GF305 peach seedlings

\begin{tabular}{lccc}
\hline Virus & $\begin{array}{c}\text { Inoculated } \\
\text { leaves }^{\mathbf{a}}\end{array}$ & $\begin{array}{c}\text { Systemic } \\
\text { leaves }^{\mathbf{a}}\end{array}$ & $\begin{array}{c}\text { Nucleotide } \\
\text { sequence }^{-}\end{array}$ \\
\hline PS MCl & $11 / 64(6.1 \%)$ & $21 / 64(32.8 \%)$ & A1395G1764 \\
(K107G231) & & & \\
PS K107S231 & $15 / 24(62.5 \%)$ & $19 / 24(79.1 \%)$ & A1395A1764 \\
PS E107S231 & $43 / 64(67.2 \%)$ & $54 / 64(84.3 \%)$ & G1395A1764 \\
PS E107G231 & $10 / 24(42.6 \%)$ & $14 / 24(58.3 \%)$ & G1395G1764 \\
\hline
\end{tabular}

${ }^{\text {a }}$ Number of infected plants assessed by enzyme-linked immunosorbent assay/number of assayed plants. Percentage of infected plants is shown in parenthesis. 

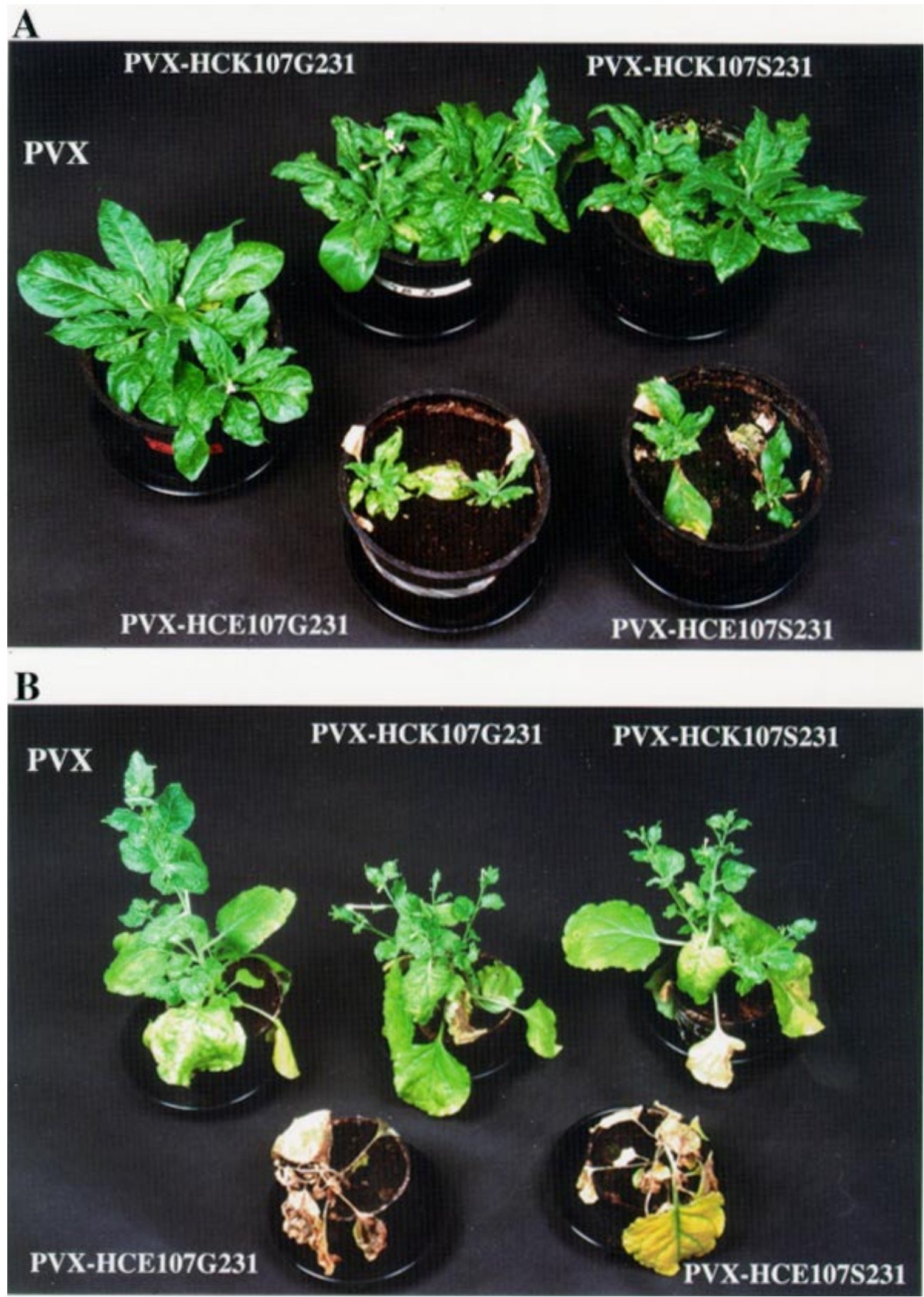

Fig. 4. Symptoms of Potato virus X (PVX)-Plum pox virus HC chimeric viruses in different herbaceous species. A, Nicotiana clevelandii and B, Nicotiana benthamiana plants were infected with PVX, PVX-HCK107G231, PVX-HCK107S231, PVX-HCE107G231, and PVX-HCE107S231. Photographs were taken 23 days postinoculation. 
although the alteration of symptom expression by a natural mutation in the HC coding sequence also has been described (Gal-On and Raccah 1999). Our work extends the HC analysis to protein variants detected in a single isolate. The two heterogeneities found in the PPV-PS population affect amino acids located in the central region of HC protein (amino acids 107 and 231) (Fig. 5). In contrast to most of the mutations at this region of other potyviruses mentioned above, amino acid changes in these positions seem to affect symptom severity, yet without an obvious effect on virus accumulation and movement. A similar effect on symptom expression without apparent changes in replication or movement efficiencies was observed for a point mutation in the HC protein of Zucchini yellow mosaic virus. HC, therefore, could have a role in symptom induction that is not entirely linked to its involvement, direct or indirect, in virus amplification and movement. Nevertheless, as discussed above, we cannot discount the possibility that small changes in replication or movement rates could be responsible for the symptom differences. Although the complex relationships between $\mathrm{HC}$ roles in virus amplification and movement, symptom induction, and interference with plantdefense mechanisms are still open questions that require further research, the results of this paper demonstrate that variation of single nucleotides of $\mathrm{HC}$ might be especially relevant for virulence evolution in natural potyvirus infections.

\section{MATERIALS AND METHODS}

Virus sources.

The original PPV-PS isolate came from an infected peach tree and was provided by Dr. Rankovic of the Institute of Fruticola Research, Čačak, Yugoslavia. It was maintained by passages in the herbaceous host $N$. clevelandii. Young herbaceous plants were inoculated by rubbing leaves dusted with Carborundum with crude sap from infected plants $(1 \mathrm{~g}$ of leaf tissue in $2 \mathrm{ml}$ of $5 \mathrm{mM}$ sodium phosphate, $\mathrm{pH}$ 7.2).

For woody plant infection, the first leaves of the juvenile seedlings (approximately 20 days after sowing) were dusted with Carborundum and inoculated mechanically with crude sap extracts of infected $N$. benthamiana $(1 \mathrm{~g}$ in $10 \mathrm{ml}$ of $30 \mathrm{mM}$ sodium phosphate, $0.2 \%$ sodium diethyldithiocarbamate, $\mathrm{pH}$ 7.2).

\section{Lesion passage.}

Crude extracts of $N$. clevelandii leaves infected with PPVPS ( $1 \mathrm{~g}$ in $2 \mathrm{ml}$ of $5 \mathrm{mM}$ sodium phosphate, $\mathrm{pH}$ 7.2) were manually inoculated onto Carborundum-dusted leaves of $C$. foetidum plants, a local lesion host for PPV. Virus from single lesions were amplified in $N$. clevelandii plants. In some cases, local lesion passage was repeated two times to obtain efficient virus isolation. Six subisolates, PS 4.1.4, PS 5.1.3, PS 1.3.1, PS 2.1.1, PS $10_{7}$, and PS $10_{2}$, were selected in this way for further studies.

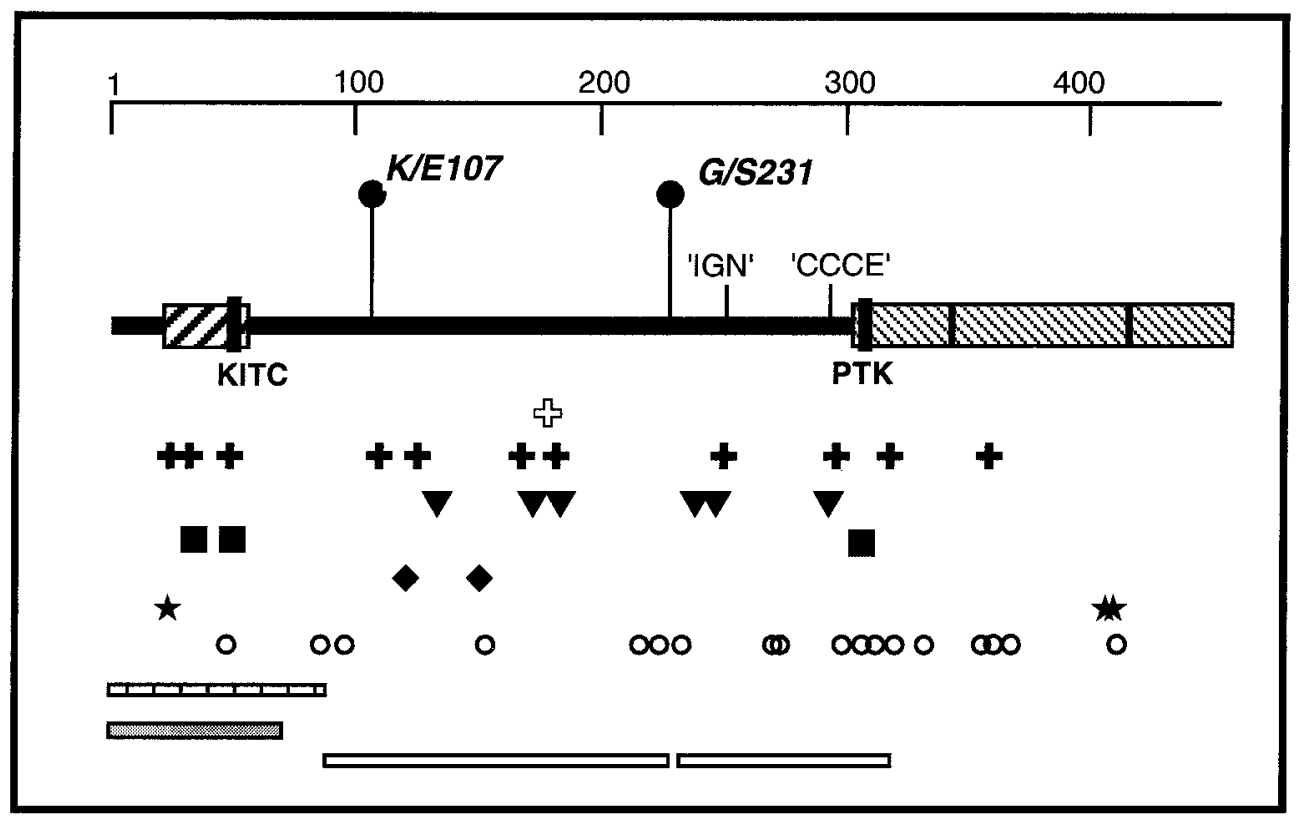

Fig. 5. Schematic representation of the potyvirus HC protein showing the position of functional domains, conserved sequence motifs, and mutations that do or do not affect different activities of the protein. Right striped box: cysteine-rich region (Robaglia et al. 1989). Left striped box: protease domain (black lines mark the position of the catalytic cysteine and histidine residues) (Oh and Carrington 1989). Clear bars: RNA binding domains A and B (Urcuqui-Inchima et al. 2000). Vertical striped bar: Tobacco etch virus (TEV) region not essential for virus replication and movement (Dolja et al. 1993). Shaded bar: domain responsible for homodimerization of the protein (Urcuqui-Inchima et al. 1999). White cross: Zucchini yellow mosaic virus (ZYMV) mutation that affects symptom expression (Gal-On and Raccah 2000). Black crosses: Tobacco vein mottling virus (TVMV) and TEV mutations that affect symptom expression and genome amplification (Atreya and Pirone 1993; Atreya et al. 1992; Cronin et al. 1995; Kasschau et al. 1997; Klein et al. 1994). Triangles: TVMV and TEV mutations that affect genome amplification and abolish long-distance movement (Cronin et al. 1995; Kasschau et al. 1997; Klein et al. 1994). Squares: TVMV and ZYMV mutations that affect aphid transmission (Atreya and Pirone 1993; Atreya et al. 1992; Huet et al. 1994). Black diamonds: TEV mutations that affect Potato virus X-potyvirus synergism (Shi et al. 1997). Stars: TVMV and TEV lethal mutations (Atreya and Pirone 1993; Kasschau et al. 1997; Klein et al. 1994). Open circles: TVMV and TEV mutations that do not significantly affect symptom expression, virus movement, or genome amplification (Atreya and Pirone 1993; Atreya et al. 1992; Kasschau et al. 1997). Vertical lines with filled circle caps: position of sequence heterogeneities of the Plum pox virus-PS subisolates. 
Amplification of viral sequences and sequencing analysis.

The full genome sequence of the subisolate PS 4.1.4 was determined on overlapping partial cDNA fragments amplified by IC-PCR (Wetzel et al. 1992) from extracts of infected $N$. clevelandii plants. The reverse transcription (RT)-PCR step of IC-PCR was carried out with the Titan kit (Roche Molecular Biochemicals, Mannheim, Germany), which includes a highfidelity DNA polymerase. After separation by electrophoresis in agarose gels, the amplified fragments were purified with a QIAEX II kit (Qiagen, Hilden, Germany) and sequenced with the fmol kit (Promega, Madison, WI, U.S.A.).

Partial genome sequences of the other PPV-PS subisolates were obtained following the same strategy. Nucleotide numbering is in accordance with the PPV-PS sequence deposited in the EMBL database, accession no. AJ243957.

\section{Plasmid constructions.}

pGPPVPS: The construction of pGPPVPS has been described previously (Sáenz et al. 2000).

pGPPVPSE107S231: A cDNA fragment of 1,406 nucleotides (PPV nucleotides 1,014 to 2,419) was amplified by ICPCR (see above) from $N$. clevelandii plants infected with PPV-PS 4.1.4. This fragment was digested with BsaBI and BglII (PPV nucleotides 1,334 to 2,312) and inserted into p5H1, which contains the first 3,602 nucleotides of the PPV-PS genome (Sáenz et al. 2000), giving rise to p5-H1E107S231. pGPPV-PSE107S231 was obtained by triple ligation of $B g l \mathrm{II}-$ $B g l$ I (from PPV nucleotide 2,312 to the pGEM3 vector sequence), $B g l \mathrm{I}-\mathrm{StyI}$ (from pGEM3 vector sequence to the PPV nucleotide 692) from pPPVPS, and StyI-BglII (PPV nucleotides 692 to 2,311) from p5-H1E107S231.

pGPPVPSE107G231: The StyI-BglII cDNA fragment (PPV nucleotides 692 to 2,311) of PPV-PS 1.3.1 was cloned in pGPPVPS, yielding pGPPVPSE107G231 with the strategy described above for pGPPVPSE107S231.

pGPPVPSK107S231: This plasmid was obtained by inserting the Bpu1102I-VspI fragment (PPV nucleotides 371 to 1,489 ) from pGPPVPS and the $V s p \mathrm{I}-B g l \mathrm{II}$ fragment (PPV nucleotides 1,489 to 2,312) from pGPPVPSK107S231 into pGPPVPS digested with $B g l \mathrm{II}$ and $B p u 1102 \mathrm{I}$.

pPVX-HCK107G231 and pPVX-HCE107S231: pP2C2S derives from pGC3 (Chapman et al. 1992) and contains a fulllength copy of the PVX genome placed under the control of a phage $\mathrm{T} 7$ promoter. It was used as a vector for cloning within this virus.

cDNA fragments encoding $\mathrm{HC}$ protein were amplified by PCR from full-length PPV-PS cDNA clones with the oligodeoxynucleotides 5'-ACCATGGCGTCCGACCCAGGC-3' and 5'-GCGTCGACTATCCAACCAGGTATG-3' as primers. These oligodeoxynucleotides supply artificial initiation and termination codons (shown in bold) to control the translation of the HC coding region and a SalI restriction site to facilitate cloning (underlined letters). After blunting the ends with T4 DNA polymerase and SalI digestion, the fragments amplified from pGPPVPS and pGPPVPSE107S231 were cloned in pP2C2S digested with EcoRV and SalI, giving rise to pPVXHCK107G231 and pPVX-HCE107S231, respectively. Sequences cloned in this insertion site were thus placed under the control of a duplicated PVX CP subgenomic promoter.

pPVX-HCK107S231 and pPVX-HCE107G231: These plasmids were obtained by fragment exchanges between pPVX-
HCK107G231 and pPVX-HCE107S231 with the VspI restriction site of the PPV HC coding region and the SalI and Sse 8387I sites of $\mathrm{pP} 2 \mathrm{C} 2 \mathrm{~S}$.

The accuracy of the constructions was verified by restriction analysis and sequencing of all regions amplified by PCR.

\section{In vitro transcription and inoculation of plants.}

The recombinant plasmids were linearized with $P v u \mathrm{II}$ (pGPPVPS-derived clones) or with SpeI (pP2C2S-derived clones), followed by phenol-chloroform extraction and ethanol precipitation. Capped full-length transcripts were synthesized from these templates with the T7 Cap-Scribe kit (Roche Molecular Biochemicals). Yield and integrity of the transcripts were analyzed by agarose gel electrophoresis.

Three primary leaves per plant were dusted with Carborundum and inoculated mechanically with $1.5 \mu \mathrm{l}$ of the transcription reaction mixture diluted 1:1 with $5 \mathrm{mM}$ sodium phosphate buffer ( $\mathrm{pH} 7.2)$.

Virus accumulation was assessed by Western blot analysis and by DASI-ELISA with the REALISA kit (Durviz, Valencia, Spain).

\section{ACKNOWLEDGMENTS}

We thank D. Baulcombe of the Sainsbury Laboratory, Norwich, U.K., for providing the $\mathrm{pP} 2 \mathrm{C} 2 \mathrm{~S}$ clone, E. Domínguez for technical assistance, and T. P. E. Doyle for critical reading of the manuscript. This work was supported by grants BIO98-0769 from the CICYT, BIO4-CT97-2300 and -2356 from the Biotechnology Program of the European Union, and HF1996-0024 from the Spanish-French Picasso Program.

\section{LITERATURE CITED}

Anandalakshmi, R., Pruss, G., Ge, X., Marathe, R., Mallory, A. C., Smith, T. H., and Vance, V. B. 1998. A viral suppressor of gene silencing in plants. Proc. Natl. Acad. Sci. USA 95:13079-13084.

Asensio, M. 1996. El viru de la sharka (plum pox virus): Caracterización, diagnóstics y detección mediante anticuerpos monoclonales especificos. Ph.D. thesis. Universidad Politécnica de Valencia (E.T.S.I. Agrónomos), Spain.

Atreya, C. D., and Pirone, T. P. 1993. Mutational analysis of the helper component-proteinase gene of a potyvirus: Effects of amino acid substitutions, deletions, and gene replacement on virulence and aphid transmissibility. Proc. Natl. Acad. Sci. USA 90:11919-11923.

Atreya, C. D., Atreya, P. L., Thornbury, D. W., and Pirone, T. P. 1992. Site-directed mutations in the potyvirus HC-Pro gene affect helper component activity, virus accumulation, and symptom expression in infected tobacco plants. Virology 191:106-111.

Bousalem, M., Candresse, T., Quiot-Douine, L., and Quiot, J. B. 1994. Comparison of three methods for assessing plum pox virus variability: Further evidence for the existence of two major groups of isolates. J. Phytopathol. 142:163-172.

Brigneti, G., Voinnet, O., Li, W. X., Ji, L. H., Ding, S. W., and Baulcombe, D. C. 1998. Viral pathogenicity determinants are suppressors of transgene silencing in Nicotiana benthamiana. EMBO J. 17:6739-6746

Candresse, T., Cambra, M., Dallot, S., Lanneau, M., Asensio, M., Gorris, M. T., Revers, F., Macquaire, G., Olmos, A., Boscia, D., Quiot, J. B., and Dunez, J. 1998. Comparison of monoclonal antibodies and polymerase chain reaction assays for the typing of isolates belonging to the $\mathrm{D}$ and $\mathrm{M}$ serotypes of plum pox potyvirus. Phytopathology 88:198-204.

Carrington, J. C., Cary, S. M., Parks, T. D., and Dougherty, W. G. 1989. A second proteinase encoded by a plant potyvirus genome. EMBO J. 8:365-370.

Cervera, M. T., Riechmann, J. L., Martin, M. T., and García, J. A. 1993. $3^{\prime}$-Terminal sequence of the plum pox virus PS and o6 isolates: Evidence for RNA recombination within the potyvirus group. J. Gen. Vi- 
rol. 74:329-334.

Chapman, S., Kavanagh, T., and Baulcombe, D. 1992. Potato virus X as a vector for gene expression in plants. Plant J. 2:549-557.

Crescenzi, A., D’Aquino, L., Comes, S., Nuzzaci, M., Piazzolla, P., Boscia, D., and Hadidi, A. 1997. Characterization of the sweet cherry isolate of plum pox potyvirus. Plant Dis. 81:711-714.

Cronin, S., Verchot, J., Haldeman-Cahill, R., Schaad, M. C., and Carrington, J. C. 1995. Long-distance movement factor: A transport function of the potyvirus helper component proteinase. Plant Cell 7:549-559.

Dallot, S., Labonne, G., Boeglin, M., Quiot-Douine, L., Quiot, J. B., and Candresse, T. 1998. Peculiar plum pox potyvirus D-populations are epidemic in peach trees. Acta Hortic. 472:355-365.

Dolja, V. V., Herndon, K. L., Pirone, T. P., and Carrington, J. C. 1993. Spontaneous mutagenesis of a plant potyvirus genome after insertion of a foreign gene. J. Virol. 67:5968-5975.

Domingo, E., and Holland, J. J. 1997. RNA virus mutations and fitness for survival. Annu. Rev. Microbiol. 51:151-178.

Domingo, E., Escarmis, C., Sevilla, N., Moya, A., Elena, S. F., Quer, J., Novella, I. S., and Holland, J. J. 1996. Basic concepts in RNA virus evolution. FASEB J. 10:859-864.

Drake, J. W. 1993. Rates of spontaneous mutations among RNA viruses. Proc. Natl. Acad. Sci. USA 90:4171-4175.

Eigen, M., and Schuster, P. 1979. The hypercycle: A principle of natural self organization. Springer-Verlag, New York.

Gal-On, A. and Raccah, B. 2000. A point mutation in the FRNK motif of the potyvirus helper component-protease gene alters symptom expression in cucurbits and elicits protection against the severe homologous virus. Phytopathology 90:467-473.

Hammond, J., and Kamo, K. K. 1995. Effective resistance to potyvirus infection conferred by expression of antisense RNA in transgenic plants. Mol. Plant-Microbe Interact. 8:674-682.

Holland, J. J., Torre, J. C. D. L., and Steinhauer, D. A. 1992. RNA virus population as quasispecies. Curr. Top. Microbiol. Immunol. 176:1-20.

Huet, H., Gal-On, A., Meir, E., Lecoq, H., and Raccah, B. 1994. Mutations in the helper component protease gene of zucchini yellow mosaic virus affect its ability to mediate aphid transmissibility. J. Gen. Virol. 75:1407-1414

Kasschau, K. D., and Carrington, J. C. 1998. A counterdefensive strategy of plant viruses: Suppression of posttranscriptional gene silencing. Cell 95:461-470.

Kasschau, K. D., Cronin, S., and Carrington, J. C. 1997. Genome amplification and long-distance movement functions associated with the central domain of tobacco etch potyvirus helper componentproteinase. Virology 228:251-262.

Klein, P. G., Klein, R. R., Rodríguez-Cerezo, E., Hunt, A., and Shaw, J. G. 1994. Mutational analysis of the tobacco vein mottling virus genome. Virology 204:759-769.

López-Moya, J. J., Fernández-Fernández, M. R., Cambra, M., and García, J. A. 2000. Biotechnological aspects of plum pox virus. J. Biotechnol. 76:121-136.

Maia, I. G., and Bernardi, F. 1996. Nucleic acid-binding properties of a bacterially expressed potato virus $\mathrm{Y}$ helper component-proteinase. J. Gen. Virol. 77:869-877.

Mansky, L. M., and Temin, H. M. 1995. Lower in vivo mutation rate of human immunodeficiency virus type I than that predicted from the fidelity of purified reverse transcriptase. J. Virol. 69:5087-5094.

Nemchinov, L., Hadidi, A., Maiss, E., Cambra, M., Candresse, T., and Damsteegt, V. 1996. Sour cherry strain of plum pox potyvirus (PPV): Molecular and serological evidence for a new subgroup of PPV strains. Phytopathology 86:1215-1221.

Oh, C. S., and Carrington, J. C. 1989. Identification of essential residues in potyvirus proteinase HC-Pro by site-directed mutagenesis. Virology 173:692-699.

Revers, F., Le Gall, O., Candresse, T., and Dunez, J. 1996. Frequent occurrence of recombinant potyvirus isolates. J. Gen. Virol. 77:19531965.

Revers, F., Le Gall, O., Candresse, T., and Maule, A. 1999. New advances in understanding the molecular biology of plant/potyvirus interactions. Mol. Plant-Microbe Interact. 12:367-376.

Riechmann, J. L., Laín, S., and García, J. A. 1992. Highlights and prospects of potyvirus molecular biology. J. Gen. Virol. 73:1-16.

Robaglia, C., Durand-Tardif, M., Tronchet, M., Boudazin, G., AstierManifacier, S., and Casse-Delbart, F. 1989. Nucleotide sequence of potato virus Y (N strain) genomic RNA. J. Gen. Virol. 70:935-947.

Rojas, M. R., Zerbini, F. M., Allison, R. F., Gilbertson, R. L., and Lucas, W. J. 1997. Capsid protein and helper component proteinase function as potyvirus cell-to-cell movement proteins. Virology 237:283-295.

Sáenz, P., Cervera, M. T., Dallot, S., Quiot, L., Quiot, J. B., Riechmman, J. L., and García, J. A. 2000. Identification of a pathogenicity determinant of Plum pox virus in the sequence encoding the C-terminal region of protein $\mathrm{P} 3+6 \mathrm{~K}_{1}$. J. Gen. Virol. 81:557-566.

Shi, X. M., Miller, H., Verchot, J., Carrington, J. C., and Vance, V. B. 1997. Mutations in the region encoding the central domain of helper component-proteinase (HC-Pro) eliminate potato virus $\mathrm{X} /$ potyviral synergism. Virology 231:35-42.

Thornbury, D. W., Hellmann, G. M., Rhoads, R. E., and Pirone, T. P. 1985. Purification and characterization of potyvirus helper component. Virology 144:260-267.

Urcuqui-Inchima, S., Walter, J., Drugeon, G., German-Retana, S., Haenni, A.-L., Candresse, T., Bernardi, F., and Le Gall, O. 1999. Potyvirus helper component-proteinase self-interaction in yeast twohybrid system and delineation of the interaction domain involved. Virology 258:95-99.

Urcuqui-Inchima, S., Maia, I. G., Arruda P, Haenni, A.-L., and Bernardi, F. 2000. Deletion mapping of the potyviral helper componentproteinase reveals two regions involved in RNA binding. Virology 268:104-111.

Vance, V. B., Berger, P. H., Carrington, J. C., Hunt, A. G., and Shi, X. M. 1995. 5' Proximal potyviral sequences mediate potato virus $\mathrm{X} /$ potyviral synergistic disease in transgenic tobacco. Virology 206:583-590.

Wetzel, T., Candresse, T., Ravelonandro, M., Delbos, R. P., Mazyad, H., Aboul-Ata, A. E., and Dunez, J. 1991. Nucleotide sequence of the $3^{\prime}$ terminal region of the RNA of the El Amar strain of plum pox potyvirus. J. Gen. Virol. 72:1741-1746.

Wetzel, T., Candresse, T., Macquaire, G., Ravelonandro, M., and Dunez, J. 1992. A highly sensitive immunocapture polymerase chain reaction method for plum pox potyvirus detection. J. Virol. Methods 39:27-37. 


\section{Erratum}

\section{Vol. 14, No. 3, 2001}

(Pages 278-287)

In the manuscript entitled "Pathogenicity Determinants in the Complex Virus Population of a Plum pox virus Isolate," by Pilar Sáenz, Laurence Quiot, Jean-Bernard Quiot, Thierry Candresse, and Juan Antonio García, incorrect data appeared in Table 3, line 3. An emended table appears below. There was also a mistake in the numbering of the amino acid sequence of HC protein. Residues referred to throughout the paper as 107 and 231 actually correspond to positions 109 and 232, respectively. The authors and MPMI apologize for the errors.

Table 3. Genome and protein localization of sequence heterogeneities found in different Plum pox virus PS subisolates

\begin{tabular}{|c|c|c|c|c|c|c|c|c|}
\hline \multicolumn{4}{|c|}{ Gene-nucleotide position ${ }^{a}$} & \multirow[b]{2}{*}{ Subisolate $^{\mathrm{a}}$} & \multicolumn{4}{|c|}{ Protein-amino acid position } \\
\hline $\mathrm{HC} 1,395^{b}$ & HC 1,764 & NIb 7,793 & $\mathrm{CP} 8,711^{\mathrm{c}}$ & & HC 109 & HC 232 & NIb 257 & CP 45 \\
\hline$G$ & $A$ & $C$ & $A$ & PS 4.1.4, PS 5.1.3 & Glu & Ser & Ser & Leu \\
\hline G & G & A & $\mathrm{C}$ & PS 1.3.1, PS 2.1.1 & Glu & Gly & Ser & Phe \\
\hline$G$ & $A$ & $A$ & $C$ & $P S 10_{7}, P S 10_{2}$ & Glu & Ser & Ser & Phe \\
\hline A & G & A & $\mathrm{C}$ & PS MCl & Lys & Gly & Ser & Phe \\
\hline
\end{tabular}

${ }^{a}$ Italic and plain text indicates severe and mild isolates, respectively.

${ }^{\mathrm{b}} \mathrm{HC}=$ helper component protein; $\mathrm{NIb}=$ nuclear inclusion $\mathrm{b}$ protein.

${ }^{\mathrm{c}} \mathrm{CP}=$ capsid protein. 